\title{
УДК: 519.816
}

\author{
Ігор Олександрович Ляченко (кандидат військових наук) ${ }^{1}$ \\ Оксана Миколаӥвна Ключак 2 \\ Свімлана Петрівна Зелінська
}

${ }^{1}$ Київський Національний економічний університет імені Вадима Гетьмана, Киӥв, Украӥна ${ }^{2}$ Національний університет оборони Украӥни імені Івана Черняховського, Київ, Україна

\section{БЕЗПЕРЕРВНІ ДИНАМІЧНІ МОДЕЛІ НАДІЙНОСТІ ПРОГРАМНОГО ЗАБЕЗПЕЧЕННЯ ІНФОРМАЦІЙНО- УПРАВЛЯЮЧИХ СИСТЕМ СПЕЦІАЛЬНОГО ПРИЗНАЧЕННЯ}

\begin{abstract}
Розглядається можливість застосування безперервних динамічних моделей для очінки надійності програмного забезпечення інформаційно-управляючих систем спеціального призначення. За умови досягнення високої надійності, сучасна техніка стає ефективною та конкурентоспроможною. Саме від показника надійності похідними будуть інші, не менш важливі показники - якість, живучість, безпека, готовність - а це основні показники, щуо визначають ефективність інформаційно-управляючих систем спеціального призначення. Переважна більшість досліджень в цььому напрямку поняття надійності програмного забезпечення виділяє окремо, тому, що при застосуванні понять надійності до програмних засобів варто враховувати особливості $i$ відмінності изих об'єктів від традиційних технічних систем, для яких спочатку розроблялася теорія надійності. Принципова відмінність програм від техніки, та технічних систем зокрема, полягає в тому, щэо програма не зношується з плином часу, а навпаки, виявляються помилки, які не були знайдені раніше, програмне забезпечення з часом вдосконалюється і покрашується.
\end{abstract}

Ключові слова: безперервні динамічні моделі; оцінка надійності; програмне забезпечення; інформачійно-управляючі системи спеціального призначення.

\section{Вступ}

Розвиток інформаційних технологій та комп'ютерної техніки та всебічне проникнення ії в усі сфери життєдіяльності людини передбачає постановку нових задач для розробників програмного забезпечення. Програмні продукти стають дедалі складнішими, багатокомпонентними і вимагають спеціалізованого підходу.

За умови досягнення високої надійності, сучасна техніка стає ефективною та конкурентоспроможною. Саме від показника надійності похідними будуть інші, не менш важливі показники - якість, живучість, безпека, готовність - а це основні показники, що визначають ефективність інформаційноуправляючих систем спеціального призначення.

Постановка проблеми. Переважна більшість досліджень в цьому напрямку поняття надійності програмного забезпечення (ПЗ) виділяє окремо [1], тому, що при застосуванні понять надійності до програмних засобів варто враховувати особливості і відмінності цих об'єктів від традиційних технічних систем, для яких спочатку розроблялася теорія надійності. Принципова відмінність програм від техніки, та технічних систем зокрема, полягає в тому, що програма не зношується 3 плином часу, а навпаки, виявляються помилки, які не були знайдені раніше, програмне забезпечення 3 часом вдосконалюється і покращується.
Аналіз останніх досліджень і публікацій. Для розв'язання завдань оцінки та прогнозування надійності на даний час використовують цілий ряд різноманітних моделей надійності ПЗ [1-8].

Виклад основного матеріалу дослідження

Модель надійності програмного забезпечення передбачає побудову математичної моделі для оцінки залежності надійності програмного забезпечення від певних параметрів. Такими параметрами є частота помилок, які дозволяють оцінити якість систем реального часу, що функціонують в безперервному режимі, і в той же час отримувати непряму інформацію про надійність ПЗ [3].

На сьогоднішній день виділяють наступні типи моделей надійності [9]:

аналітичні;

динамічні;

статичні;

емпіричні.

Найбільш широко на сьогоднішній день використовуються динамічні моделі $[2,4,10]$ на основі неоднорідного пуассонового процесу, в яких вихідні дані збираються в процесі тестування ПЗ протягом фіксованих або випадкових часових інтервалів. Кожен інтервал являє собою стадію, на якій виконується деяка послідовність тестів та виявляється деяка кількість помилок. 
В даній роботі пропонується розглянути особливості безперервних динамічних моделей оцінки надійності програмного забезпечення. Проаналізувати їх переваги та недоліки 3 метою виявлення доцільності їх застосування для оцінки надійності програмного забезпечення інформаційно-управляючих систем спеціального призначення.

\section{Модель Jelinski-Moranda.}

Дана модель [11] побудована на припущенні, що час до чергової відмови розподілено експоненціально, а інтенсивність відмов програмного забезпечення пропорційна кількості помилок, що залишились в програмі.

Відповідно до цих припущень імовірність безвідмовної роботи програмного забезпечення як функція часу $t_{i}$ дорівнює [4]

$$
\mathrm{P}\left(\mathrm{t}_{\mathrm{i}}\right)=\mathrm{e}^{-\lambda_{\mathrm{i}} \mathrm{t}_{\mathrm{i}}},
$$

де: $\lambda_{\mathrm{i}}-$ інтенсивність відмов.

$$
\lambda_{\mathrm{i}}=\mathrm{C}_{\mathrm{D}}(\mathrm{N}-(\mathrm{i}-1)),
$$

де: $\mathrm{C}_{\mathrm{D}}$ - коефіцієнт пропорційності;

$\mathrm{N}$ - апріорна кількість помилок.

Розрахунок часу $t_{i}$ починається 3 моменту останньої відмови програмного забезпечення.

За методом максимуму правдоподібності, позначимо через $\mathrm{k}$ номер відмови, що прогнозується, та отримаємо функцію правдоподібності вигляду

$$
\mathrm{F}=\prod_{\mathrm{i}=1}^{\mathrm{k}-1} \mathrm{C}_{\mathrm{D}}(\mathrm{N}-\mathrm{i}+1) \mathrm{e}^{-\mathrm{C}_{\mathrm{D}}(\mathrm{N}-\mathrm{i}+1) \mathrm{t}_{\mathrm{i}}}
$$

Логарифмічна функція правдоподібності має вигляд

$$
\mathrm{L}=\ln \mathrm{F}=\sum_{\mathrm{i}=1}^{\mathrm{k}-1}\left[\ln \left(\mathrm{C}_{\mathrm{D}}(\mathrm{N}-\mathrm{i}+1)\right)-\mathrm{C}_{\mathrm{D}}(\mathrm{N}-\mathrm{i}+1) \mathrm{t}_{\mathrm{i}}\right]
$$

Відповідно умови знаходження екстремума

$$
\begin{aligned}
\frac{\mathrm{dL}}{\mathrm{dC}_{\mathrm{D}}} & =\sum_{\mathrm{i}=1}^{\mathrm{k}-1}\left[\frac{1}{\mathrm{C}_{\mathrm{D}}}-(\mathrm{N}-\mathrm{i}+1) \mathrm{t}_{\mathrm{i}}\right]=0, \\
\frac{\mathrm{dL}}{\mathrm{dN}} & =\sum_{\mathrm{i}=1}^{\mathrm{k}-1}\left[\frac{1}{\mathrm{~N}-\mathrm{i}+1}-\mathrm{C}_{\mathrm{D}} \mathrm{t}_{\mathrm{i}}\right]=0 .
\end{aligned}
$$

Відповідно можна отримати

$$
\mathrm{C}_{\mathrm{D}}=\frac{\sum_{\mathrm{i}=1}^{\mathrm{k}-1} \frac{1}{\mathrm{~N}-\mathrm{i}+1}}{\sum_{\mathrm{i}=1}^{\mathrm{k}-1} \mathrm{t}_{\mathrm{i}}} .
$$

Зробивши відповідну підстановку отримуємо

$$
(\mathrm{k}-1) \frac{\sum_{\mathrm{i}=1}^{\mathrm{k}-1} \mathrm{t}_{\mathrm{i}}}{\sum_{\mathrm{i}=1}^{\mathrm{k}-1} \frac{1}{\mathrm{~N}-\mathrm{i}+1}}=\sum_{\mathrm{i}=1}^{\mathrm{k}-1}(\mathrm{~N}-\mathrm{i}+1) \mathrm{t}_{\mathrm{i}}
$$

При відомих значеннях $\mathrm{k} ; \mathrm{t}_{1}, \mathrm{t}_{2}, \ldots, \mathrm{t}_{\mathrm{k}}$ можна знайти значення параметрів моделі $\mathrm{C}_{\mathrm{D}}$ та $\mathrm{N}$, a потім інтенсивність відмов, час між відмовами $\mathrm{t}_{\mathrm{k}+1}$, імовірність безвідмовної роботи через час $\mathrm{t}_{\mathrm{k}+1}$ після останньої відмови.

Модель перехідних ймовірностей Маркова дозволяє отримати оцінки і прогнози імовірного числа помилок, які будуть виправлені в заданий час, на основі попереднього моделювання інтенсивності помилок, що трапляються 1 , а також прийнятої системи виправлення помилок, що працює 3 інтенсивністю $\mathrm{m}$. Модель дозволяє отримати прогнози для готовності $\mathrm{A}(\mathrm{t})$ i надійності $\mathrm{R}(\mathrm{t})$ системи програмного забезпечення.

В даній моделі приймаються наступні основні:

будь-яка помилка розглядається як випадкова i без градації наслідків, які вона породжує;

інтенсивність прояву помилок постійна i рівна 1;

інтенсивність виправлення помилок постійна i рівна $\mathrm{m}$;

час переходу системи 3 одного стану в інший нескінченно малий.

Надійність системи $\mathrm{R}(\mathrm{t})$ визначається імовірністю відсутності відмови в інтервалі $[0, \mathrm{t}]$ :

$$
\mathrm{R}(\mathrm{t})=\mathrm{P}\left\{\mathrm{t}^{\prime} \geq \mathrm{t}\right\} .
$$

Під готовністю системи на час $t$ розуміється імовірність того, що система знаходиться в робочому стані на час $t$ :

$$
\mathrm{A}(\mathrm{t})=\mathrm{P} \text {. }
$$

Будь-який стан системи визначається рядом перехідних імовірностей $\left\{\mathrm{P}_{\mathrm{ij}}\right\}$, де $\mathrm{P}_{\mathrm{ij}}$ означає імовірність переходу зі стану $i$ в стан $j$ та не залежить від попередніх та наступних станів системи, крім станів $i$ та $j$.

Вираз для готовності системи на час $\mathrm{t}(\mathrm{t} \succ 0)$ отримуємо на підставі визначення

$$
\mathrm{A}(\mathrm{t})=\sum_{\mathrm{k}=0}^{\infty} \mathrm{P}_{\mathrm{n}-\mathrm{k}}(\mathrm{t})
$$

де: $\mathrm{n}$ - кількість помилок у системі.

Готовність системи на час $t$ визначається як результат простої суми складання усіх ймовірностей станів зайнятості.

Надійність системи залежить від ступеня іiі налагодження, тобто чим вище ступінь налагодження системи, тим більше очікувана надійність. Припустимо, що до моменту $t$ система тільки що увійшла до стану ( $\mathrm{n}-\mathrm{k})$, тобто помилка $k$ тільки що усунена. Назвемо цей час як $t$. Тоді в інтервалі часу $\left(0, \mathrm{~T}_{\mathrm{k}}+1\right)$, де в $\mathrm{t}=\mathrm{T}_{\mathrm{k}}+1$ може виявитися помилка $(\mathrm{k}+1)$ при прийнятій постійній інтенсивності прояву помилок $1_{\mathrm{k}}$.

На підставі формули функції надійності, що породжує імовірність відсутності відмов в інтервалі часу від 0 до $t, \mathrm{R}(\mathrm{t})=\mathrm{e}^{-\lambda \mathrm{t}}$, отримуємо вираз для надійності:

$$
\mathrm{R}_{\mathrm{k}}(\tau)=\mathrm{e}^{-\lambda_{\mathrm{k}} \mathrm{t}} ; \quad 0 \leq \tau \leq \mathrm{T}_{\mathrm{k}+1} ; \quad \mathrm{k}=0,1,2, \ldots .
$$




\section{Висновки й перспективи подальших} досліджень

Розглянуті безперервні динамічні моделі оцінки надійності програмного забезпечення маючи деякі недоліки (поведінка системи прогнозується під час функціонування у

\section{Лimepamypa}

1 А.М.Попов Основы теории надежности / Попов А.М., Гуров С.В. / - СПб.: БХВ - Петербург, 2006. - 704 с.

2. Липаев В.В. Надежность программных средств / Липаев В.В. / - М.: СИНТЕГ, 1998. - 232 с. 3. Тайер Т. Надежность программного обеспечения / Тайер Т., Липов М., Нельсон Э. / Пер. с англ. - М.: МИР, 1981. 323 с. 4. Монахов Ю.М. Функциональная устойчивость информационных систем. В 3 ч. Ч. 1. Надежность программного обеспечения : учеб. пособие / Ю. М. Монахов / Владим. гос. ун-т. - Владимир : Изд-во Владим. гос. ун-та, 2011. - 60 с. - ISBN 978-5-99840189-3. 5. Ляшенко I.O. Розрахунок надійності функціонування інформаційно-управляючих систем спеціального призначення / Ляшенко I.О., Кузьмічов Д.А., Кравченко І.Ю. / Збірник наукових праць / інститут проблем моделювання в енергетиці НАНУ. № 64. К.: 2012. - С. 31-35. 6. Ляшенко I.O. Аналіз динамічних дискретних моделей оцінки надійності программного забезпечення / Ляшенко I.О., Кузьмічов Д.А., Кравченко І.Ю. / Збірник наукових праць / інституг проблем моделювання в енергетиці НАНУ. № 65. К.: 2012. - С. 41-45є 7. Ляшенко I.О. Аналіз середньому; не передбачається внесення нових помилок при виправлені виявлених) дають можливість прогнозувати характеристики системи шляхом моделювання до початку роботи, або після закінчення роботи системи. А це, на сьогодні дуже актуально.

статичних моделей оцінки надійності программного забезпечення інформаційно-управляючих систем спеціального призначення / Ляшенко I.O., Кузьмічов Д.А. / Моделювання та інформаційні технології, збірник наукових праць / інститут проблем моделювання в енергетиці НАНУ. № 65. К.: 2012. - С. 47-51. 8. Ляшенко I.O. Аналіз безперервних динамічних моделей оцінки надійності программного забезпечення інформаційно-управляючих систем спеціального призначення / Ляшенко I.O., Кузьмічов Д.А. / Моделювання та інформаційні технології, збірник наукових праць / інститут проблем моделювання в енергетиці НАНУ. № 66. К.: 2012. - С. 58-62. 9. Казарин О.В. Теория и практика защиты программ / Казарин О.В./ - М.:МГУЛ, 2004. - 450 с. 10. К.-Y. Саi, D.-B. Hu, Ch.-G. Bai, H. Hu, T. Jing Does software reliability growth behavior follow a non-homogeneous Poisson process // Information and Software Technology. Vol. 50. - 2008. - P. 1232-1247. 11. Z. Jelinski and P. Moranda Software reliability research // in Statistical Computer Performance Evaluation. - W. Freiberger, Ed. New York: Academic. - 1972. - P. 465-484.

\title{
НЕПРЕРЫВНЫЕ ДИНАМИЧЕСКИЕ МОДЕЛИ НАДЕЖНОСТИ ПРОГРАММНОГО ОБЕСПЕЧЕНИЯ ИНФОРМАЦИОННО-УПРАВЛЯЮЩИХ СИСТЕМ СПЕЦИАЛЬНОГО НАЗНАЧЕНИЯ
}

\author{
Игорь Александрович Ляшенко (кандидат военных наук) \\ Оксана Николаевна Ключак ${ }^{2}$ \\ Светлана Петровна Зелинская
}

\footnotetext{
${ }^{1}$ Киевский Национальный экономический университет имени Вадима Гетьмана, Киев, Украина

${ }^{2}$ Национальный университет обороны Украины имени Ивана Черняховского, Киев, Украина
}

Рассматривается возможность применения непрерывных динамических моделей для оценки надежности программного обеспечения информационно-управляющих систем специального назначения. При условии достижения высокой надежности, современная техника становится эффективной и конкурентоспособной. Именно показателя надежности производными будут другие, не менее важные показатели - качество, живучесть, безопасность, готовность - а это основные показатели, определяюшие эффективность информащионно-управляющих систем специального назначения. Подавляющее большинство исследований в этом направлении понятие надежности программного обеспечения выделяет, потому, что при применении понятий надежности к программным средствам следует учитывать особенности и различия этих объектов от традиционных технических систем, для которых изначально разрабатывалась теория надежности. Принципиальное отличие программ от техники, и технических систем в частности, заключается в том, что программа не изнашивается со временем, а наоборот, выявляются ошибки, которые не были найдены ранее, программное обеспечение со временем совериенствуется и улучшается.

Ключевые слова: непрерывные динамические модели; оиенка надежности; программное обеспечение; информачионно-управляющие системы специального назначения.

\section{UNLIMITED DYNAMIC MODELS ADVANCED SOFTWARE INFORMATION-CONTROLLING SYSTEMS FOR SPECIAL APPOINTMENT}

\author{
Igor Lyashenko (candidate of military sciences) ${ }^{1}$ \\ Oksana Kliuchak ${ }^{2}$ \\ Svitlana Zelinska ${ }^{2}$
}


${ }^{1}$ Kiev National Economic University named after Vadim Getman, Kiev, Ukraine

${ }^{2}$ National Defense University of Ukraine named by Ivan Cherniakhovsky, Kyiv, Ukraine

The possibility of using continuous dynamic models to assess the reliability of special-purpose information management systems is considered. With the achievement of high reliability, modern technology becomes efficient and competitive. It is the reliability indicator that the derivatives will be other, equally important indicators - quality, survivability, safety, availability - and these are the main indicators that determine the effectiveness of special-purpose information and control systems. The overwhelming majority of research in this direction highlights the concept of software reliability, because when applying the concepts of reliability to software, one should take into account the features and differences of these objects from traditional technical systems for which the theory of reliability was originally developed. The fundamental difference between programs and technology, and technical systems in particular, is that the program does not wear out over time, but rather, errors that were not found earlier are detected, the software improves and improves over time.

Key words: continuous dynamic models; reliability assessment; software; information and control systems for special purposes.

\section{References}

1 A.M.Popov Fundamentals of the theory of reliability / Popov A.M., Gurov S.V. / - St. Petersburg: BHV Petersburg, 2006 .-- 704 p. 2. Lipaev V.V. Reliability of software tools / Lipaev V.V. / - M .: SINTEG, 1998 .- 232 p. 3. Thayer T. Reliability of software / Thayer T., Lipov M., Nelson E. / Per. from English - M .: MIR, 1981. - 323 p. 4. Monks Yu.M. Functional stability of information systems. At 3 hours. Part 1. Software reliability: textbook. allowance / Yu. M. Monakhov / Vladim. state un-t Vladimir: Publishing house Vladim. state University, 2011 .- 60 p. - ISBN 978-5-9984-0189-3. 5. Lyashenko I.O. Rozrahunok nadinosti funktsionuvannya informatsiynogoverning systems of special purpose / Lyashenko I.O., Kuzmichov D.A., Kravchenko I.Yu. / Zbirnik naukovih prac / Institute of Model Modeling in Energy of NASU. No. 64. $\mathrm{K}$.: 2012. - S. 31-35. 6. Lyashenko I.O. Analysis of dynamic discrete models for evaluating the reliability of software / Lyashenko I.O., Kuzmichov D.A., Kravchenko I.Yu. / Zbirnik naukovih prac / Institute of Model Modeling in Energy of NASU. No. 65. C.: 2012. - S. 41-45e 7. Lyashenko I.O. Analysis of static models of evaluation of software security and information-control systems of special designation / Lyashenko I.O., Kuzmichov D.A. / Modeling and information technology, science institute / Institute for Modeling Problems in Energy of NASU. No. 65. K .: 2012. - S. 47-51. 8. Lyashenko I.O. Analysis of uninterrupted dynamic estimation models of software security and information-control systems of special designation / Lyashenko I.O., Kuzmichov D.A. / Modeling and information technology, science institute / Institute for Modeling Problems in Energy of NASU. No. 66. K .: 2012. - S. 58-62. 9. Kazarin O.V. Theory and practice of program protection / Kazarin O.V. / - M.: MGUL, 2004. - 450 p. 10. K.-Y. Cai, D.-B. Hu, Ch.-G. Bai, H. Hu, T. Jing Does software reliability growth behavior follow a nonhomogeneous Poisson process // Information and Software Technology. - Vol. 50. - 2008. - P. 1232-1247. 11. Z. Jelinski and P. Moranda Software reliability research // in Statistical Computer Performance Evaluation. - W. Freiberger, Ed. - New York: Academic. - 1972. - P. 465-484. 